Review

\title{
Recent advances of drug delivery nanocarriers in osteosarcoma treatment
}

\author{
Shang-Yu Wang\#, Hong-Zhi Hu\#, Xiang-Cheng Qing\#, Zhi-Cai Zhang, and Zeng-Wu Shao ${ }^{\bowtie}$ \\ Department of Orthopedics, Union Hospital, Tongji Medical College, Huazhong University of Science and Technology, Wuhan 430022, China \\ \#These authors contributed equally to this work. \\ $\triangle$ Corresponding author: Zeng-Wu Shao, Department of Orthopedics, Union Hospital, Tongji Medical College, Huazhong University of Science and \\ Technology, Wuhan, 430022, China. Tel: 13971021748. Fax: 86-027-85726489. E-mail: szwpro@163.com. \\ (c) The author(s). This is an open access article distributed under the terms of the Creative Commons Attribution License (https://creativecommons.org/licenses/by/4.0/). \\ See http://ivyspring.com/terms for full terms and conditions.
}

Received: 2019.05.11; Accepted: 2019.09.18; Published: 2020.01.01

\begin{abstract}
Osteosarcoma is the most common primary malignant bone tumor mainly occurred in children and adolescence, and chemotherapy is limited for the side effects and development of drug resistance. Advances in nanotechnology and knowledge of cancer biology have led to significant improvements in developing tumor-targeted drug delivery nanocarriers, and some have even entered clinically application. Delivery of chemotherapeutic agents by functionalized smart nanocarriers could protect the drugs from rapid clearance, prolong the circulating time, and increase the drug concentration at tumor sites, thus enhancing the therapeutic efficacy and reducing side effects. Various drug delivery nanocarriers have been designed and tested for osteosarcoma treatment, but most of them are still at experimental stage, and more further studies are needed before clinical application. In this present review, we briefly describe the types of commonly used nanocarriers in osteosarcoma treatment, and discuss the strategies for osteosarcoma-targeted delivery and controlled release of drugs. The application of nanoparticles in the management of metastatic osteosarcoma is also briefly discussed. The purpose of this article is to present an overview of recent progress of nanoscale drug delivery platforms in osteosarcoma, and inspire new ideas to develop more effective therapeutic options.
\end{abstract}

Key words: Drug delivery, nanocarriers, osteosarcoma, stimuli-response, tumor-targeted

\section{Introduction}

Chemotherapy is an important approach in cancer therapy. Effective treatment of cancers needs accurate delivery of an enough intracellular dose of chemo-drugs to kill the cancer cells [1]. And chemotherapy for cancer is a delicate balance between response and toxicity, while low-dosing fails to obtain effective effects, over-dosing leads to excessive systemic toxicity [2]. Furthermore, drug distribution efficiency from plasma to tumors is affected by some physiologic parameters, such as competitive drug uptake by liver, excretion of small molecule drugs by urine, drug inactivation by binding to proteins, and low stability of drug in fluids [3]. Therefore, nanoscale drug delivery systems have been widely studied in recent years for tumor-targeted drug therapy due to their potentials to enhance and preserve the clinical therapeutic effects of chemo-drugs with less side effects by improving their protection, absorption, penetration and distribution [2, 4-6]. Nanocarriers for drug delivery have several advantages $[2,7,8]$ : (1) protecting the drug from being degraded and prolonging the retention time in the body; (2) increasing the solubility of some hydrophobic drugs; (3) targeted delivery and controlled release of drugs by nanoparticles modification to keep the drug concentration in tumor sites and maximize therapeutic effects; (4) possibility of multiple drug delivery to achieve synergistic therapeutic response, or application of combination therapy such as chemo-photothermal therapy.

Osteosarcoma is the most common primary malignant bone tumor mainly occurred in childhood 
and adolescence [9]. Due to the introduction of chemotherapy and advances in surgical technology, the 5-year survival rate of those with local osteosarcoma has improved to approximate 70\% [9, 10]. However, current chemo-drugs commonly used in treatment of osteosarcoma are limited for their side effects and development of resistance [11]. To address these drawbacks and to increase the efficacy of chemotherapy, a variety of nanoplatforms for targeted drug or gene delivery has been extensively investigated in osteosarcoma, and nanotechnology has been proposed as a promising strategy for osteosarcoma treatment [7, 12-14].

In this review, we retrospectively summarized the recent advances of nanocarriers for targeted drug delivery in osteosarcoma. We discuss the commonly used types of drug delivery nanoparticles, controlled drug release upon different stimuli, and nanocarriers modification strategies for targeted drug delivery. The application of nanoparticles in the management of metastatic osteosarcoma is also briefly discussed. And we hope this review will provide readers a general understanding of current status in osteosarcoma nanomedicine, and inspire further investigations in novel drug delivery nanosystems for osteosarcoma treatment.

\section{Types of nanoparticles}

Nanosized drug delivery systems can be roughly classified into organic and inorganic carriers [7]. Organic nanocarriers reported for osteosarcoma drug delivery mainly include liposomes, polymers, micelles, and dendrimers. And inorganic nanocarriers mainly include metallic nanoparticles, mesoporous silica nanomaterials, carbon-based nanomaterials, and calcium phosphates carriers. However, it is difficult to obtain multifunctional and intelligent nanocarriers from single nanomaterial. Thus, current designed drug delivery nanosystems are usually nanocomposites of different kinds of materials.

\section{Organic nanocarriers}

\section{Liposomes}

Liposomes are spherical vesicles with a hydrophilic cavity surrounded by one or several lipid bilayers that allows the encapsulation of drugs with different solubility. Hydrophobic drugs can be entrapped by the lipid bilayer and hydrophilic drugs can be encapsulated in the central aqueous core $[3,15$, 16]. Liposomal formulations are the first nanosized drug delivery carriers that have been successfully translated into clinical applications. And many liposomes for cancer therapy have been approved by the US Food and Drug Administration, or have underwent different clinical trials, including in osteosarcoma treatment [16-18]. In addition to the inherent advantages such as biocompatibility and biodegradability, novel liposomes with different modification exhibit better selectivity, less systemic clearance, longer circulatory time, and controllable drug release [19].

A variety of nanoscale liposomes for anti-osteosarcoma agent delivery have been explored in the past years. Clinical trials have demonstrated that inclusion of liposomal muramyl tripeptide phosphatidyl ethanolamine (L-MTP-PE) could clinically and significantly improved the long-term survival of osteosarcoma patients [20]. Normal liposomes can be recognized and cleared by the reticuloendothelial system (RES). Surface modification with biocompatible hydrophilic polymers, such as polyethylene glycol (PEG), could help liposomes to escape from RES and prolong the circulation time [17, 19]. Recently, a PEGylated liposomal nanocarrier co-loaded with gemcitabine and clofazimine was reported and its antiosteosarcoma effects were investigated [21]. The hydrophilic gemcitabine was encapsulated in the aqueous core and hydrophobic clofazimine sequestered in lipid bilayer. And this co-loaded nanoscale formulation was stable and exhibited synergistic cytotoxicity on osteosarcoma cells in vitro [21]. Liu Y et al [22] used PEGylated liposomes coated with gold nanoshell to deliver betulinic acid, which is a kind of hydrophobic natural anti-tumor drug. Other smart PEGylated liposomal formulations containing DOX, a commonly used chemo-drug, were also reported in osteosarcoma treatment $[23,24]$. There are still some drawbacks of PEGylation including disturbance of interaction between liposomes and tumor cells, and induction of anti-PEG IgM antibodies which is considered to be responsible for accelerated blood clearance $(\mathrm{ABC})$ phenomenon after repeated injection of PEGylated liposomes [17]. Thus, other polymers such as chitooligosaccharides (COS) have been investigated for liposome modification [25]. This COS modified DOX-loaded liposomes showed good biocompatibility, prolonged circulation time, enhanced intracellular uptake, and improved anti-osteosarcoma effect. In addition to delivering anti-tumor drugs, liposomes are also appropriate vectors for gene delivery. PEGylated cationic liposomes are commonly used for siRNA loading and delivering, and could increase the stability of siRNA [26, 27].

\section{Polymers}

Many different polymers have been widely used for anti-cancer drug delivery and have received increased interest in recent years. Commonly used 
polymers from synthetic such as poly lactideco-glycolic acid (PLGA) and PEG, or from natural origin such as hyaluronan and chitosan, demonstrate good biocompatibility and biodegradability. A range of biodegradable polymeric drug delivery systems designed for localized or systemic administration of therapeutic agents has been under clinical trials or approved for cancer treatment $[28,29]$.

Different biodegradable polymers have been used for designing safe and efficient nanocarriers for anti-osteosarcoma agent delivery. Suksiriworapong et al. [30] reported an easily synthesized methotrexate (MTX) conjugate with poly glycerol adipate (PGA). The MTX-PGA conjugates could self-assemble into nanoparticles that were physically and chemically stable but enzymatically degradable to release MTX. In another study, a natural polymer keratin nanoparticle functionalized with a photosensitizer Chlorin-e6, was prepared for Paclitaxel (PTX) loading [31]. This natural biocompatible keratin, has exclusive tri-peptidic sequences, such as the "Arg-Gly-Asp" (RGD) and "Leu-Asp-Val" (LDV) sequences, that can specifically recognize vitronectin integrin receptors overexpressed in osteosarcoma cells [31]. In addition to being used directly as drug delivery carriers, polymers are commonly used for nanocarriers modification to improve their stability, biocompatibility and specificity. For example, PEG-functionalized PLGA and polymer-lipid nanoparticles could prolong the systemic circulation time [32, 33]. The natural polymer hyaluronic acid (HA) was an attractive ligand for targeted drug delivery to CD44-overexpressing tumors, and HA modification could enhance tumor cell internalization of these nanocarriers [34, 35]. Due to its excellent biocompatibility and biodegradability, an in situ crosslinked nanogel based on HA has been synthesized for codelivery of DOX and cisplatin, two of the most widely clinically used chemo-drugs with proved synergistic effects, to osteosarcoma [36].

\section{Micelles}

Micelles are usually formed by amphiphilic polymers and have attracted considerable attention as promising nanocarriers for drug delivery. Polymeric micelles consist of a core and shell structure. In principle, the micelle core part is usually hydrophobic and can encapsulate poorly water-soluble agent, whereas the outer shell is able to stabilize the micelles in aqueous environment and can be modified with stimuli-responsive or tumor-targeting moieties [3739]. The size of these self-assembled micelles can be easily controlled by varying the length of the hydrophobic blocks. Compared with liposomes, micelles are considered to be more suitable for poorly water-soluble agents [39].

Several studies have reported different kinds of micelles for osteosarcoma treatment [40-42]. Fang et al. [42] designed and synthesized an osteosarcoma targeted polymeric micelle carrier which was self-assembled from RGD-modified PEG-block-poly (trimethylene carbonate) (RGD-PEG-PTMC) amphiphilic block copolymers, for DOX delivery. Stewart A. Low et al. [40] designed a different DOX conjugate micellar delivery system for osteosarcoma therapy. In this study, the hydrophilic D-aspartic acid octapeptide was used as bone targeting agent and hydrophilic micelle corona; The DOX was loaded via an acid-sensitive hydrazone bond and served as the hydrophobic center to stabilize the micelle because of its hydrophobic nature as well as an ability to ח-п stack with itself. The insertion of 11-aminoundecanoic acid (AUA) between DOX and the aspartic acid octapeptide could vary the hydrophobicity of this micelle-forming unimer [40]. Another study reported that a polymeric micelle was synthesized to carry an arsenical drug, PENAO. The drug was chemically conjugated to the micelle surface to avoid drug leakage and premature release without altering PENAO's arsenous acid residue activity [41]. Recently, an amphiphilic block copolymer PEG-poly[2-(methylacryloyl) ethylnicotinate] (PEG-PMAN) was prepared to deliver Zinc phthalocyanine $(\mathrm{ZnPc})$, a poorly soluble photosensitizer for cancer photodynamic therapy (PDT). The formed polymeric micelles dramatically improved the solubility, blood circulation time and cell uptake of $\mathrm{ZnPc}$, and exhibited excellent photodynamic therapeutic effects both in vitro and in vivo [43].

Even if micelles are highly stable in aqueous environment due to their low critical micellar concentration, they may also have a tendency to be dissociated in dilution or high ionic strength. A way to overcome this problem is introducing the cross-linking bridges in the hydrophobic core or in the hydrophilic shell, and thus regulating the drug release $[38,44]$.

\section{Dendrimers}

Dendrimers are nanoscale, globular, radially symmetric, water-soluble macromolecules with well-defined sizes, branched structures, and high density of modifiable functional groups [15, 45]. Furthermore, the abundant tertiary amines in dendrimers facilitates the release of nucleic acid or drugs from endosomes through a "proton sponge" effect $[45,46]$. Due to the above properties, dendrimers are attractive nanocarriers for drug and gene delivery. Drugs can be either encapsulated in 
their internal core by noncovalent interactions or conjugated to their surface functionalities by covalent linkages [46]. And cationic dendrimers are also ideal nanocarriers for gene delivery because the abundant cationic groups not only provide a variety of nucleic acid attaching sites but also increase the gene transfection efficiency [46-48]. However, highly positively charged dendrimers could strongly interact with the negatively charged cell membranes and cause cytoplasmic contents leakage and subsequent lysis, which raises concern regarding their safety [46, 49]. Surface modification is a commonly used strategy to reduce the charge and overcome these drawbacks.

Dendrimers has been investigated as chemo-drug or gene delivery systems in osteosarcoma. Recently, a new type of nanogels containing DOX was synthesized by incorporating generation 5 (G5) PAMAM dendrimers and DOX into alginate (AG) nanogels [50]. The presence of G5 dendrimers improved the stability, DOX loading capacity and drug release sustainability of the nanogels. Meanwhile, coating of AG could shield the charge of the dendrimers and improved the biocompatibility of the dendrimers Furthermore, the researchers found the DOX-loaded nanogels could be effectively internalized by human osteosarcoma cells and intracellularly delivered DOX to exert its cytotoxicity [50]. Dendrimers were also investigated as gene delivery vectors in osteosarcoma. A triazine-modified dendrimer G5-DAT66 has been prepared and used for TRAIL gene delivery [51]. This modified gene vector showed good water solubility and more superior transfection efficiency than commercially transfection reagents such as Lipofectamine 2000 and SuperFect, and significantly inhibited the osteosarcoma growth in vitro and in vivo.

\section{Inoganic nanocarriers}

\section{Metallic nanocarriers}

Metallic nanocarriers can be pure metallic particles such as gold, silver, and copper; or metallic compound such as oxides and Mxene; or hybrid polymers that consist of metal ions or clusters such as metal organic frameworks (MOFs) $[15,52,53]$.

Among the pure metallic nanoparticles, gold and silver nanoparticles are the most commonly investigated in osteosarcoma therapeutics. Due to the remarkable properties such as high surface area to volume ratio, stable nature, multi-functionalization, facile synthesis, high permeability and retention effect, and photothermal conversion capability, gold nanoparticles (AuNPs) have long been considered as a potential tool for cancer treatment [54, 55]. A study from Rahim et al. showed that spherical glycogenic AuNPs could inhibit the growth of osteosarcoma cell [56]. Steckiewicz et al. [57] assessed the effect of AuNPs shape on their cytotoxicity against osteosarcoma cells and demonstrated that the AuNPs stars were more cytotoxic than rods and spheres. AuNPs as drug or gene delivery carriers were also reported in osteosarcoma [58-60]. Gold nanoshells were reported to have strong absorption in near infrared (NIR) region and high photothermal conductivity. Liu $\mathrm{Y}$ et al. designed a gold nanoshell-coated liposomal drug delivery system [22]. Upon NIR irradiation, the nanocarriers could rapidly transform NIR light to heat, increase cellular uptake, and trigger the release of drug. In addition to AuNPs, the cytotoxic effect of silver nanoparticles (AgNPs) were also investigated in osteosarcoma [61,62]. Reactive oxygen species (ROS) generation leading to mitochondria-dependent apoptosis was considered as the possible mechanisms of AgNP-induced cytotoxicity.

Metallic compound-based nanoparticles reported in osteosarcoma treatment are mainly metallic oxides, and these metallic oxide nanoparticles can serve as intrinsic therapeutic agents without the need of loading chemotherapy drug. For example, the anti-cancer effect of titanium dioxide (TiO2), terbium oxide (Tb2O3), zinc oxide $(\mathrm{ZnO})$ and cerium oxide $(\mathrm{CeO} 2)$ nanoparticles has been evaluated verified in osteosarcoma cells [63-65]. However, the biocompatibility and antitumor effect in vivo were not further explored in these studies. Among the metallic oxide nanoparticles, iron oxide such as ferroferric oxide ( $\mathrm{Fe} 3 \mathrm{O} 4)$ was the most commonly investigated nanomaterials in osteosarcoma. And these nanoparticles were mostly used for thermal therapy due to its ability to convert the energy of magnetic field into heat [66-68]. Besides, iron oxide nanoparticles could also be used for drug delivery because of its biocompatibility. Popescu et al. successfully fabricated Gemcitabine conjugated Fe3O4 nanoparticles. And this nanoconjugate showed promising results regarding their cytotoxicity against human osteosarcoma cells [69]. The superparamagnetic properties of iron oxide could increase the cellular uptake of loaded cargos under an external magnetic field [70]. However, Fe3O4 nanoparticles were reported to have a tendency to agglomerate in biological conditions [68]. Therefore, it is necessary to modify the $\mathrm{Fe} 3 \mathrm{O} 4$ nanoparticles' surface to overcome the problem when used for different biomedical applications. Other metallic nanomaterials mentioned above (Mxene and MOFs) as drug delivery systems have not been reported in osteosarcoma treatment. 


\section{Mesoporous silica nanocarriers}

Mesoporous silica nanoparticles (MSNs) have attracted considerable attention for drug or gene delivery because of their excellent characteristics including simple fabrication process, uniform morphology, variable particle size, modifiable surface, tunable pore size and volume, and FDA recognized biosafety [71, 72]. The large surface area and the porous structure enable MSNs to have high loading capacity with different agents. Surface modification with different functional groups allows MSNs to realize tumor targeting and controlled drug release [72].

The use of MSNs as drug or gene delivery systems in osteosarcoma have also been widely reported. Shahabi et al. [73] evaluated the influence of MSNs surface modification on the encapsulation and release of DOX, as well as cancer cell response in the absence or presence of serum proteins. They demonstrated that, in the presence of serum proteins, sulfonate functionalization of MSNs showed both increased doxorubicin loading and in vitro doxorubicin delivery rate, compared with unfunctionalized MSNs, antibody-conjugated MSNs or even free DOX. Hartono and colleagues [70] designed a new type of PEI modified and iron oxide loaded large pore MSNs for gene delivery to osteosarcoma cells. The magnetic property of iron oxide promotes the cellular uptake of MSNs under an external magnetic field. PEI covalently linked on the MSNs improves the particle's affinity against siRNA and cells membrane which can also increase cell uptake. The 'proton sponge effect' of PEI enables the particle to effectively deliver the siRNA and escape from endosome, thus increasing the transfection and silencing effects. Another research also fabricated a similar type of magnetic core-shell silica nanoparticles to delivery siRNA [74]. An additional acid-liable coating with tannic acid could further protect the siRNA and serve as a pH-responsive releasing switch. Paris et al. [75] reported a smart hierarchical ultrasound-responsive MSN for drug delivery. The PEG shell will be detached from the MSNs by ultrasound-induced temperature increase, exposing the positively charged surface, which favors the cell internalization of the particles and enhance the cytotoxic effect. Martínez-Carmona et al. [76] developed a tumor-targeted and PH-responsive MSNs loaded with DOX for osteosarcoma treatment. This nanoscale drug carrier could improve the antitumor effectiveness and decrease the toxicity to normal cells. Studies from Lu et al. [77] demonstrated that functionalized smart MSNs showed a high specificity for osteosarcoma, and exhibited significantly synergistic photothermalchemotherapeutic properties.

Because of the superior nature such as safety, high drug loading capacity, controllable drug release and modifiable surface, MSNs are considered to have the potential to be a more promising platform for cancer therapy compared to other inorganic nanocarriers such as copper, gold, and silver which exhibit some cytotoxicity. However, there is still a long approach before clinical translation and commercialization [71, 72].

\section{Carbon-based nanocarriers}

Carbon-based nanomaterials such as carbon nanotubes (CNTs), graphene oxide (GO), mesoporous carbon, and carbon dots, have drawn considerable attention and been extensively investigated for cancer therapy because of their good physicochemical properties including easily-modified surface, exellent photo-thermal conversion ability, supramolecular п-п stacking, and high adsorption ability [78-82].

Among these different carbon nanomaterials, GO and CNTs were the mostly reported in osteosarcoma. Tang et al. [83] evaluated the toxicity and underlying mechanisms of GO on osteoasrcoma cells in the absence of fetal bovine serum which excluded the formation of the blood protein-graphene corona and enabled the direct interaction of GO with the cell membrane, and they found that different mechanisms including ROS generation, apoptosis, and autophagy were involved in GO-induced anti-osteosarcoma effect. Another study [84] described the metabolomic response of osteosarcoma cells to GO-mediated hyperthermia. Upon NIR irradiation, the levels of glutamate and uridine nucleotides decreased, and glycerophosphocholine increased, which may reflect laser-induced membrane damage. Recently, a PH-sensitive graphene oxide-chitosan nanoparticle was developed to carry siRNA, and this nanocarrier exhibited effective release of siRNA in acidic condition [85]. Li et al. [86] reported that anti-HER2 antibody trastuzumab (TRA) was noncovalently conjugated to GO to form stable TRA /GO nano-complexes. And this TRA /GO nanoscale formulation demonstrated significantly enhanced HER2-binding activity and effective anti-osteosarcoma capacity.

CNTs have also attracted considerable attention for cancer therapy. Yan et al. [87] constructed a 3D structured graphene/single-walled carbon nanotubes (G/SWCNT) hybrid by combining single-walled carbon nanotubes and graphene, and evaluated its cytotoxicity of on osteosarcoma cells. The G/SWCNT hybrids showed less cytotoxic than graphene and SWCNTs, and the G/SWCNT hybrids-induced 
apoptosis was through ROS-mediated mitochondrial pathway. Polymers were commonly used to modify CNTs to reduce the cytotoxicity [88, 89]. Zhang et al. [89] fabricated a polyamidoamine (PAMAM) dendrimers functionalized multi-walled carbon nanotubes (MWCNTs). The hybrids exhibited good dispersibility and stability in aqueous solution, excellent biomolecule immobilization ability, and reduced cytotoxicity. PLGA modified CNTs were developed by Cheng et al. [88] for delivering pro-apoptotic protein caspase-3. This conjugate showed a high transfection rate and significant anti-osteosarcoma effect in vitro. Another research demonstrated that SWCNTs could specifically inhibit the process of TGF $\beta 1$-induced osteosarcoma cells dedifferentiation, prevent the stem cell phenotypes acquisition and reduce the osteosarcoma stem cells viability [90].

Though many exciting advances in the field of carbon-based nanomaterials have been made, yet there were relatively few investigations of these nanomaterials as drug delivery systems in osteosarcoma. More focused and systematic research on tumor targeting, toxicity and pharmacokinetics of these nanomaterials is needed in osteosarcoma.

\section{Calcium phosphates nanocarriers}

Calcium phosphates (CaP) nanoparticles, particularly hydroxyapatite nanoparticles (HANPs), are considered as promising nanocarriers to bone tissues because they are biocompatible, biodegradable, non-immunogenic, $\mathrm{PH}$-sensitive and facilely modifiable, and have shown to be preferentially accumulated in bone tissues [91-94]. CaP-based nanoparticles have been widely used for delivery of anticancer drugs in osteosarcoma treatment [92, 93, 95-97].

Son et al. [93] fabricated a series of CaP-alginate nanocomposites loading different anticancer drugs. The CaP-polymer-drug complexes were formed by hydrogen bonding and electrostatic interaction. These drug-loaded nanocomposites showed a prolonged drug release at $\mathrm{PH} 7.4$, and faster release at $\mathrm{PH} 4.5$, and exhibited anticancer activity on osteosarcoma cells. Based on the idea that like should cure like and that bone diseases and deformities are best targeted and treated using one or more components of bone itself, hydroxyapatite, a mineral matrix that resembles the crystallographic structure of natural bone, has been considered as an ideal carrier for drug delivery to bone diseases, such as osteosarcoma $[92,95,97]$. In addition, HANPs have been reported to possess the ability for inhibiting cancer cell growth in vitro and in vivo, and show less cytotoxicity to normal cells [98]. Wu et al. [97] modified HANPs with bisphosphonate as a bone targeting moiety to deliver anticancer drug JQ1, a small-molecule bromodomain inhibitor. Loading JQ1 onto HANPs can delay its release and prolong the retention in the body. Though the JQ1-loaded HANPs exhibited a promising selectivity, being more toxic to osteosarcoma cells than to primary fibroblasts, the comparatively low loading efficiency of hydrophobic JQ1 onto ionic HANPs has been a drawback of this therapy. Wang et al. [96] developed a novel kind of biodegradable and $\mathrm{pH}$-sensitive selenium-doped hydroxyapatite nanoparticles (Se-HANs), and evaluated their anti-osteosarcoma effects and mechanisms in vitro and in vivo. The selenium released from Se-HANs could induce tumor cell apoptosis through an inherent caspase-dependent apoptosis pathway synergistically orchestrated with ROS generation.

\section{Strategies for osteosarcoma-targeted drug delivery}

Targeted drug delivery generally means delivery of the intravenously administered drugs to the target site, e.g. tumors. Targeted drug delivery systems are designed to facilitate drug delivery to the tumor sites with minimum side effects, and that are performed by two targeting strategies, including passive and active targeting [99] (Figure 1). Compared with free small therapeutic agents, nanocarriers can passively accumulate in tumors through the enhanced permeability and retention (EPR) effect, which is characterized by leaky blood vessels and impaired lymphatic drainage in tumor tissues, and achieve superior therapeutic efficacy, while reducing side effects $[100,101]$.

Even though nanocarriers can be passively targeted to tumor via EPR effect, it suffers from some serious limitations such as inefficient drug diffusion into tumor cells, the random nature of targeting, and the lack of EPR effect in some tumors. Thus, there is potential to improve the tumor targetability of the nanocarriers through active targeting strategies, such as ligand-mediated tumor targeting [8, 102, 103]. Ligand-functionalized nanocarriers could interact with cancer cells and be internalized via receptor-mediated endocytosis mechanism, thereby resulting in higher therapeutic effect $[102,104]$. The knowledge of tumor cell epitopes and advances in nanotechnology have allowed the development of targeted nanocarriers able to actively deliver antitumor agents to diseased area [4, 8]. Bisphosphonates [34, 97], aptamers [14], hyaluronic acid (HA) [24], folate [105], and peptides [42] have been reported to be used in designing osteosarcomatargeted drug delivery systems (Table 1). 
Table 1. Examples of osteosarcoma-targeted strategies used in drug delivery nanomaterials and the therapeutic potential

\begin{tabular}{|c|c|c|c|c|c|}
\hline NPs Types & Targets & Cargos & Tested models & Effects & Ref. \\
\hline HANPs & Medronate & JQ1 & $\begin{array}{l}\text { In vitro: } \mathrm{K} 7 \mathrm{M} 2 \text { murine } \mathrm{OS} \text { cells, and mouse } \\
\text { primary lung fibroblasts } \\
\text { In vivo: none }\end{array}$ & $\begin{array}{l}\text { In vitro: selectivity, and more toxic to OS cells than to primary } \\
\text { fibroblasts } \\
\text { In vivo: none }\end{array}$ & 97 \\
\hline LbL liposomes & alendronate & DOX & $\begin{array}{l}\text { In vitro: } 143 \mathrm{~B} \text { OS cells; } \\
\text { In vivo: } 143 \mathrm{~B} \text { xenografts in nude mice }\end{array}$ & $\begin{array}{l}\text { In vitro: rapid and effective cell uptake } \\
\text { In vivo: preferential accumulation in the xenografts, enhanced } \\
\text { chemotherapeutic effects in tumor-bearing mice, extended } \\
\text { animal survival }\end{array}$ & 107 \\
\hline BP NPs & $\mathrm{BP}$ & DOX & $\begin{array}{l}\text { In vitro: Saos- } 2 \text { OS cells; } \\
\text { In vivo: Saos- } 2 \text { subcutaneous xenograft tumor in a } \\
\text { nude mouse model }\end{array}$ & $\begin{array}{l}\text { In vitro: higher cellular uptake and therapeutic effect than free } \\
\text { DOX } \\
\text { In vivo: tumor targeting ability, prolonged retention in tumor } \\
\text { site, enhanced bone tumor toxicity }\end{array}$ & 108 \\
\hline $\begin{array}{l}\text { Lipopolymer } \\
\text { NPs }\end{array}$ & $\begin{array}{l}\text { LC09 } \\
\text { aptamers }\end{array}$ & $\begin{array}{l}\text { CRISPR/Cas9 pla } \\
\text { smids } \\
\text { encoding VEGFA } \\
\text { gRNA and Cas9 }\end{array}$ & $\begin{array}{l}\text { In vitro: } \mathrm{K} 7 \mathrm{M} 2 \text { and } \mathrm{K} 12 \text { mouse OS cells } \\
\text { In vivo: } \mathrm{BALB} / \mathrm{c} \text { nude mice bearing K7M2 } \\
\text { orthotopic xenograft }\end{array}$ & $\begin{array}{l}\text { In vitro: enhanced cellular uptake, effective gene silencing, } \\
\text { improved antitumor effects } \\
\text { In vivo: tumor cell-selective distribution and expression of } \\
\text { CRISPR/Cas9, superior tumor suppression effect }\end{array}$ & 113 \\
\hline polymeric NPs & $\begin{array}{l}\text { CD133 } \\
\text { aptamers }\end{array}$ & salinomycin & $\begin{array}{l}\text { In vitro: Saos- } 2 \mathrm{CD} 133^{+} \text {and } \mathrm{CD} 133-\mathrm{OS} \text { cells } \\
\text { In vivo: Saos- } 2 \text { subcutaneous xenograft tumor in a } \\
\text { nude mouse model }\end{array}$ & $\begin{array}{l}\text { In vitro: specifically internalized by } \mathrm{CD} 133^{+} \mathrm{OS} \text { cells, enhanced } \\
\text { cytotoxic effect to } \mathrm{CD} 133^{+} \mathrm{OS} \text { cells } \\
\text { In vivo: superior antitumor activity, decreased } \mathrm{CD} 133^{+} \text {OS cells } \\
\text { proportion }\end{array}$ & 32 \\
\hline $\begin{array}{l}\text { lipid-polymer } \\
\text { NPs }\end{array}$ & $\begin{array}{l}\text { CD133 } \\
\text { aptamers }\end{array}$ & ATRA & $\begin{array}{l}\text { In vitro: Saos- } 2 \text { (U-2OS) } \mathrm{CD} 133^{+} \text {and } \mathrm{CD} 133-\mathrm{OS} \\
\text { cells } \\
\text { In vivo: } \mathrm{BALB} / \mathrm{c} \text { nude mice bearing Saos- } 2 \\
\text { subcutaneous xenograft }\end{array}$ & $\begin{array}{l}\text { In vitro: specifically targeting to } \mathrm{CD} 133^{+} \mathrm{OS} \text { cells, enhanced } \\
\text { cytotoxic effect to } \mathrm{CD} 133^{+} \mathrm{OS} \text { cells } \\
\text { In vivo: enhanced antitumor activity, decreased } \mathrm{CD} 133^{+} \mathrm{OS} \\
\text { cells proportion }\end{array}$ & 114 \\
\hline $\begin{array}{l}\text { polymer-lipid } \\
\text { hybrid NPs }\end{array}$ & $\begin{array}{l}\text { EGFR } \\
\text { aptamers }\end{array}$ & salinomycin & $\begin{array}{l}\text { In vitro: } \mathrm{U}-2 \mathrm{OS} \text { and } \mathrm{MG} 63 \mathrm{OS} \text { cells } \\
\text { In vivo: none }\end{array}$ & $\begin{array}{l}\text { In vitro: increased cellular uptake and cytotoxic effect } \\
\text { compared with non-targeted NPs and free salinomycin, } \\
\text { decreased CD } 133^{+} \text {OS cells proportion } \\
\text { In vivo: none }\end{array}$ & 115 \\
\hline liposomes & HA & DOX & $\begin{array}{l}\text { In vitro: MG63 OS cells and Normal human } \\
\text { hepatic LO2 cells } \\
\text { In vivo: MG63 xenograft mouse model }\end{array}$ & $\begin{array}{l}\text { In vitro: preferentially internalized to MG63 over LO2 cells, } \\
\text { higher cytotoxicity to MG63 cells compared with non-HA } \\
\text { coated liposomes } \\
\text { In vivo: strong and persistent selective tumor accumulation, } \\
\text { enhanced antitumor effects }\end{array}$ & 24 \\
\hline liposomes & $\begin{array}{l}\text { HA and } \\
\text { alendronate }\end{array}$ & DOX & $\begin{array}{l}\text { In vitro: } \mathrm{MG} 63 \text { cells } \\
\text { In vivo: } \mathrm{BALB} / \mathrm{c} \text { nude mice bearing MG63 } \\
\text { orthotopic xenograft }\end{array}$ & $\begin{array}{l}\text { In vitro: rapid internalization, dual targeting liposomes were } \\
\text { more toxic than other liposomes but less toxic than free DOX } \\
\text { In vivo: enhanced tumor targeting ability and antitumor effects }\end{array}$ & 34 \\
\hline $\begin{array}{l}\text { polysaccharide } \\
\text { derivative NPs }\end{array}$ & folate & AEG-1 siRNA & $\begin{array}{l}\text { In vitro: } 143 \mathrm{~B} \text { and } \mathrm{U}-2 \mathrm{OS} \text { cells } \\
\text { In vivo: } 143 \mathrm{~B} \text { cells tumor-bearing mice models }\end{array}$ & $\begin{array}{l}\text { In vitro: enhanced cellular uptake and transfection efficiency, } \\
\text { increased anti-proliferation and anti-invasion ability } \\
\text { In vivo: enhanced tumor suppressive effects compared to } \\
\text { non-targeted nanocomplex }\end{array}$ & 121 \\
\hline $\begin{array}{l}\text { polymeric } \\
\text { micelle }\end{array}$ & RGD & DOX & $\begin{array}{l}\text { In vitro: } \mathrm{MG} 63 \text { and } \mathrm{MNNG} / \mathrm{HOS} \text { cells } \\
\text { In vivo: none }\end{array}$ & $\begin{array}{l}\text { In vitro: enhanced cell targeting ability and more effective } \\
\text { anti-tumor effect } \\
\text { In vivo: none }\end{array}$ & 42 \\
\hline MSNs & RGD & DOX & $\begin{array}{l}\text { In vitro: rat } \mathrm{UMR}-106 \text { OS cells } \\
\text { In vivo: } \mathrm{UMR}-106 \text { cells tumor-bearing mice } \\
\text { models }\end{array}$ & $\begin{array}{l}\text { In vitro: enhanced tumor cell uptake } \\
\text { In vivo: outstanding tumor targeting ability }\end{array}$ & 77 \\
\hline liposomes & YSA & DOX & $\begin{array}{l}\text { In vitro: Saos- } 2 \text { OS cells } \\
\text { In vivo: none }\end{array}$ & $\begin{array}{l}\text { In vitro: higher and more nuclear uptake than non-targeted } \\
\text { liposomes } \\
\text { In vivo: none }\end{array}$ & 122 \\
\hline
\end{tabular}

NPs, nanoparticles; HANPs, hydroxyapatite nanoparticles; JQ1, a small-molecule bromodomain inhibitor; OS, osteosarcoma; LbL, layer-by-layer; DOX, doxorubicin; BP, bisphosphonate; ATRA, all-trans retinoic acid; EGFR, epidermal growth factor receptor; HA, hyaluronic acid; AEG-1, astrocyte elevated gene-1; RGD,

arginine-glycine-aspartic acid peptide; MSNs, mesoporous silica nanoparticles; YSA, a 12- amino acid peptide which is an Ephrin A1 mimic and a ligand for EphA2.

Bisphosphonates display a pyrophosphate-like structure and exhibit affinity toward bone by chelating with divalent calcium ions $(\mathrm{Ca} 2+)$ present in the HAP matrix of the bone $[4,97,106]$. Recently, HAP nanoparticles functionalized with medronate (the smallest bisphosphonate) as a bone-targeting moiety have been reported in osteosarcomatargeted treatment [97]. Though lacking animal studies, In vitro models showed that the JQ1-loaded HANPs significantly inhibited osteosarcoma cells migration and invasion but exhibited less cytotoxicity to primary fibroblasts [97]. In addition to this, bisphosphonate-conjugated polymeric nanocarriers have been fabricated to deliver chemotherapeutic drugs to osteosarcoma, and the tumor-targeting ability and anticancer effects were evaluated In vivo. These functionalized, DOXloaded nanoparticles demonstrated enhanced, prolonged tumor accumulation and significantly improved anticancer activities compared to nontargeted DOX-loaded nanocarriers or free DOX [107-109]. However, bisphosphonates are bonetargeted rather than specifically osteosarcomatargeted, and the prolonged residence in the bone tissue may have the potency to inhibit osteoclasts and bone homeostasis $[106,110]$. 


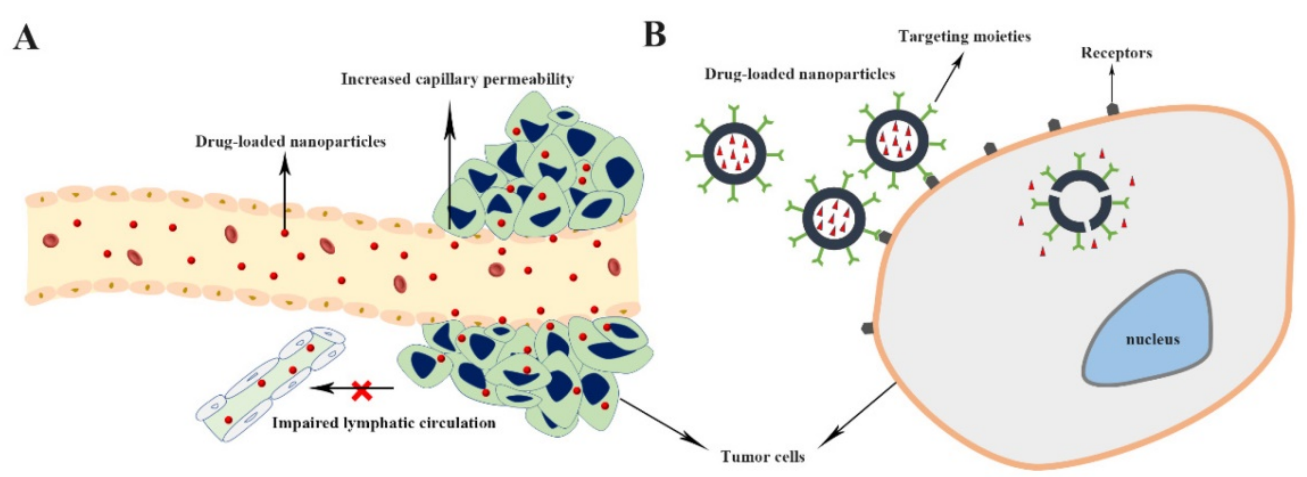

Figure 1. A simple schematic illustration of passive (A) and active (B) tumor targeting mechanism of drug delivery nanodevice.

Aptamers are short, synthetic and single-stranded DNA or RNA molecules that can specifically bind to their targets with a high affinity. And aptamers have attracted broad interest in targeted drug delivery because of their high selectivity and affinity, low immunogenicity, easy synthesis with high reproducibility, facile modification, and relatively rapid tissue penetration with no toxicity [111, 112]. Liang et al. [113] used mouse OS cells (K7M2) as target cells to screen aptamers by cell-SELEX. Mouse normal hepatocytes (AML12) and peripheral blood mononuclear cells (PBMCs) were selected as negative cells for decreasing non-specific liver and PBMCs uptake after In vivo administration. Finally, LC09 were chose as osteosarcoma cell-targeted aptamers, and LC09-modified lipopolymers loading CRISPR/Cas9 plasmids encoding VEGFA gRNA and Cas9 were developed. The LC09-fuctionalized nanocomposites achieved selective distribution of CRISPR/Cas9 in both orthotopic osteosarcoma and lung metastasis, and reduced VEGFA expression and secretion, thus inhibiting osteosarcoma malignancy and lung metastasis. CD133 is considered to be a cancer stem cells (CSCs) marker in osteosarcoma or other tumors. Accordingly, CD133 aptamers have been used as targeting ligands for tracking osteosarcoma CSCs [14, 32, 114]. CD133 aptamers-functionalized polymeric nanoparticles could specifically and efficiently deliver anticancer drugs to CD133 positive osteosarcoma CSCs, and significantly improve therapeutic effects than free drugs and non-targeted nanoparticles [32, 114]. Moreover, epidermal growth factor receptor (EGFR) aptamers were also applicated in developing osteosarcoma-targeted drug delivery carriers [14, 115].

HA, an endogenous polysaccharide, has hydroxyl and carboxylic groups, as well as an $\mathrm{N}$-acetyl group, which can be used for further chemical modifications. HA exhibits some superior physiochemical natures, such as biodegradability, biocompatibility, and non-immunogenicity [34, 116]. Many cancer cells, including osteosarcoma, are known to overexpress HA-binding receptors, such as CD44 [34, 116, 117]. Chi et al. [24] developed a redox-sensitive, HA functionalized liposomal nanocarrier to improve chemotherapy of osteosarcoma. The HA-modified liposomes demonstrated a preferential internalization into MG63 cells over normal human hepatic cells. Furthermore, the strong cellular uptake of the HA-functionalized nanoparticles by MG63 was inhibited with pre-treatment with free HA due to the competitive binding with CD44 receptors. HA-modified nanoparticles showed a persistent selective tumor accumulation, and better tumor suppressive effects compared with non-HA coated nanoparticles. Recently, researchers from the same group developed a bone- and CD44-targeted liposomal drug delivery system by conjugating alendronate and $\mathrm{HA}$ as targeting moieties, respectively, to improve the osteosarcoma-targeting ability and specific intracellular drug delivery [34].

Folate is an ideal candidate for ligand-based targeted therapy, as numerous examples of folate receptor-targeted drug delivery carriers have been reported to transport anticancer drugs into cells through receptor mediated endocytosis $[118,119]$. The overexpression of the folate receptor has been reported in many osteosarcoma xenograft samples [120]. Thus, folate-functionalized nanocarriers have been used in osteosarcoma-targeted therapy $[103,105$, 121]. Wang et al. [121] prepared a novel folate-functionalized nanoscale polysaccharide derivative as gene carrier, and assessed the safety and anti-osteosarcoma effects of this nanocomplex. Folate modification improved cellular uptake of the complexes into osteosarcoma cells, and cellular uptake decreased with free folate competition. The folate conjugated nanocomplexes demonstrated a better antitumor effect in vitro and in vivo than the nontargeted complexes. 
In addition, peptide ligands, such as RGD and YSA, have shown active osteosarcoma cell targeting ability [42, 77, 122]. RGD, a cell-affinitive peptide, is able to interact with av $\beta 3$ and av $\beta 5$ integrins, which are widely expressed in osteosarcoma cell lines. Studies from Fang et al. [42] demonstrated the RGD-modified polymeric micelles exhibited enhanced cell uptake compared to the nontargeted counterparts, displaying specific osteosarcoma cells targeting and killing ability In vitro over healthy osteoblast cells. YSA, a 12-amino acid peptide, is a ligand for ephrin type-A receptor 2 (EphA2), a surface molecule which is overexpressed in osteosarcoma cells and tissues [123]. DOX-loaded liposomes modified with YSA peptide could efficiently target human Saos2 osteosarcoma cells, and increase toxicity and cellular uptake [122].

Osteosarcoma is characterized as high-grade malignant tumor due to the high local aggressiveness and rapid systemic metastasis, especially lung metastasis, and the 5-year survival rate is only about $15-30 \%$ for patients with lung metastasis. [121, 124]. Thus, improving the prognosis of metastatic osteosarcoma remains one of the main challenges for clinicians and researchers. Nanoscale drug delivery systems can be promising strategies in the management of metastatic tumors. First, drug-loaded nanoparticles can be actively or passively delivered to primary and metastatic tumor sites. Second, well designed nanocarriers can be conjugated with certain targeting moieties, such as ligands of cell adhesion molecules which are usually overexpressed on the surface of invasive tumor cells, to combat these aggressive cells; Also, drug-loaded nanocomposites can influence the function of invasive cells to exert anti-metastatic effects. Moreover, functional drug delivery system can also re-educate the tumor environment which involves tumor cells, immune cells, stomal cell, etc., to block the initiation of metastasis [125-128]. Recently, edelfosine (ET), a potential anti-tumor agent with poor oral bioavailability and severe side effects, was encapsulated in lipid nanoparticles (ET-LNs) for osteosarcoma treatment by Gonzalez-Fernandez et al. [126]. Results of this study demonstrate that orally administered ET-LNs show significant growth inhibition effects in primary osteosarcoma cells. Besides, this drug-loaded nanosystem exhibits outstanding anti-metastatic potential as reflected by less lung metastatic nodules in mice receiving ET-LNs. Su et al. [127] designed a PEG functionalized redox-responsive dimeric paclitaxel (diPTX)-loaded cationic polycarbonates micelle (diPTX@CPGC) and evaluated the anti-tumor effects towards lung metastases via aerosol-based administration. The innovative nanocomposites exhibit well penetration capacity and significantly suppress the progression of lung metastases with minimal side effects. In another study, the effects of bovine serum albumin-Zinc phthalocyanine (BZ)-induced photodynamic therapy (PDT) on osteosarcoma were investigated [128]. Surgery together with PDT was applied in the orthotopic xenograft model, and tumor growth and recurrence were significantly inhibited. Moreover, BA-induced PDT, especially combined with autophagy inhibitor, could downregulated the expression of PD-L1 and activate the immune response, thus inhibited tumor metastasis.

\section{Controlled release of loaded drugs}

Precise and selective drug release in the tumor sites will further enhance the therapeutic efficacy and minimize the undesired side effects to normal tissues [5]. To this end, different kinds of stimuli-responsive nanocarriers have been developed. With welldesigned chemical composition or physical structure, these nanoscale drug delivery systems can be triggered by either intrinsic (e.g. $\mathrm{pH}$, redox, and enzyme) or external (e.g. light, magnetic field, and ultrasound) stimuli, thus providing spatiotemporally controllable drug release to potentiate the anti-cancer efficacy $[5,100,129]$. Here, we simply describe the application of some of these stimuli-responsive nanosystems in osteosarcoma (examples were listed in Table 2).

Table 2. Examples of stimuli-responsive nanomaterials reported in osteosarcoma

\begin{tabular}{|c|c|c|c|}
\hline Nanomaterials & Stimuli & Cargos & Ref. \\
\hline PAA-MSNs & $\mathrm{pH}$ & DOX & {$[76]$} \\
\hline F127@ZnHAP & $\mathrm{pH}$ & MTX & [132] \\
\hline ZSM-5 /CS NDs & $\mathrm{pH}$ & DOX & [131] \\
\hline liposomes & redox & DOX & $\begin{array}{l}{[24,25,} \\
34]\end{array}$ \\
\hline $\mathrm{Bi}_{2} \mathrm{~S}_{3} @ \mathrm{MSNs}$ & NIR/temperature & DOX & [77] \\
\hline MSNs & visible light & TOP & [134] \\
\hline $\begin{array}{l}\text { GelMA/(poly(NIPAM-co-AM) } \\
\text { /MNPs) nanogels }\end{array}$ & $\begin{array}{l}\text { magnetic } \\
\text { field / temperature }\end{array}$ & DOX & [138] \\
\hline
\end{tabular}

\section{pH-responsive nanocarriers}

The $\mathrm{pH}$ of blood is approximately 7.4, whereas extracellular $\mathrm{pH}$ in tumors decreases to 6.0-7.2. The $\mathrm{pH}$ in the subcellular compartments decreases to 5.06.0 in endosomes and 4.0-5.0 in lysosomes [100]. Through the introduction of acid-sensitive linkers, such as acetal, hydrazone, and glycerol ester groups, 
these $\mathrm{pH}$-sensitive nanocarriers could store and stabilize antitumor drugs at physiological $\mathrm{pH}$, but rapidly release the drugs at an acidic environment $[100,130,131]$. In a recent study, mesoporous zinc hydroxyapatite (ZnHAP) decorated with pluronic block copolymer, F127, was synthesized and used as a carrier for drug delivery [132]. The standard chemotherapeutic drug methotrexate (MTX) was grafted onto the surface of the nanoparticles via amide bond. In order to simulate the cytosol and the endosomal/lysosomal conditions, the release of MTX from the nanoparticles was evaluated under different $\mathrm{pH}$ values ranging from 4 to 7.4 in the presence of crude protease from bovine pancreas, and a large amount of MTX release was observed at $\mathrm{pH} 4.0$ [132]. Another research group has designed a multifunctional nanodevice acting as drug delivery platforms with $\mathrm{pH}$-sensitivity [76]. A polyacrylic acid (PAA) shell was anchored to the MSNs surface via an acid-cleavable acetal linker, preventing premature drug release and providing the nanocarrier of $\mathrm{pH}$-responsive capability. The drug release rate at $\mathrm{PH}$ 5.3 was much higher than PH 7.4 in both protein-free phosphate buffered saline (PBS) and proteincontaining cell culture medium. Chitosan have been used to functionalize drug carriers, enabling the composite carriers to possess $\mathrm{pH}$-responsive performances and show high drug release rate in the slightly acidic environment than in the neutral environment [131].

\section{Redox-responsive nanocarriers}

Glutathione (GSH), a highly effective antioxidant, can reduce the disulfide bonds of nanocarriers. GSH present in intracellular environments $(2-10 \mathrm{mM})$ is 100 -fold higher than that in extracellular environments $(2-10 \mu \mathrm{M})$. The concentration of GSH in the cancer cells was found to be much higher than that in normal cells. The difference in the redox potential between intracellular and extracellular concentration of GSH can be used for intracellularly controlled drug release once the nanocarrier is internalized [100, 133]. Chi et al. [24] developed redox-sensitive and tumor-targeted nanocarriers to improve chemotherapy of osteosarcoma. The liposomes were stabilized with a novel detachable PEG conjugated with cholesterol through a reducible disulfide linker. In vitro release of DOX was well controlled at physiological conditions, but a burst release of more than $60 \%$ was observed in the presence of $10 \mathrm{mM} \mathrm{GSH}$, compared to non-redox sensitive nanocarriers.

\section{Light-responsive nanocarriers}

Due to its noninvasiveness and spatiotemporal precision, light with a specific wavelength has been extensively used as an external stimulus for triggering on-demand drug delivery [129]. Recently, a visible light-responsive drug delivery MSN was designed, and drug release and antitumor activity of this smart nanocarrier were evaluated in osteosarcoma cells [134]. The pore outlets of drug-loaded MSN were blocked with porphyrin nanocaps through ROS-cleavable linkages. Upon visible light irradiation, porphyrin nanocaps could generate ROS species that are able to break the sensitive bonds and therefore triggering pore uncapping and allowing drug release. However, limited tissue penetrating capability of this short-wavelength light is the main drawback for In vitro and In vivo experiments. Near infrared (NIR) light has received considerable interest in photoactivated drug delivery because of its unique advantages such as deep tissue penetration, and limited photo damage [135]. In addition, some nanomaterials which have strong light absorption capacity in the NIR regions could convert photo energy into heat, increasing localized temperature which will trigger the drug release from nanoplatforms [135]. So far, different drug delivery nanocarriers based on NIR light absorbing nanomaterials have been reported in osteosarcoma treatment, and exhibited good NIR-responsive drug release ability [77, 121]. Lu et al. [77] developed a new type of mesoporous silica-coated bismuth sulfide nanoparticles (Bi2S3@MSN) encapsulating DOX. Researchers found that the drug release efficiency of the Bi2S3@MSN upon NIR light irradiation was significantly improved, even with an ultralow power density $(0.5 \mathrm{~W} / \mathrm{cm} 2)$. The drug loaded nanoparticle combined with NIR irradiation could significantly ablate the tumors, leading to efficient suppression of the malignant sarcoma.

\section{Magnetic field-responsive nanocarriers}

Magnetic nanoparticles (e.g. iron oxide nanoparticles) can convert magnetic energy into heat when exposed to an alternating magnetic field. The heat generated by these particles may cause structural alteration of the drug loaded nanocarriers, thus achieving an "on demand" drug release [136, 137]. The application of magnetic field-responsive nanomaterials for drug delivery was rarely reported in osteosarcoma. Jalili et al. [138] developed an injectable nanoengineered hydrogel by combining thermo-responsive polymers and magnetic nanoparticles for localized and on-demand delivery of DOX. The drug release of this nanocomposite was temperature responsive, and altering magnetic fields triggered much more drug release. However, in vivo biosafety, biodistribution, drug release kinetics, and 
antitumor effects of this drug-loaded nanogel were not evaluated in this study.

\section{Conclusions and future perspectives}

The unknown etiology, high genetic instability, large histological heterogeneity, lack of specific biomarkers, high local aggressiveness, and a rapid metastasizing potential create challenges for osteosarcoma treatment [124]. Despite the efficacy of chemo-drugs on osteosarcoma, there are still some drawbacks such as toxicity to normal tissues, development of drug resistance, and rapid blood clearance [4,124]. Thus, various nanoplatforms capable of delivering the therapeutic agent rightly to the tumor site have been developed to improve the therapeutic effects and minimize side effects. In this review, we discussed different nanocarriers that are commonly used as emerging tools for the treatment of osteosarcoma. Although exciting progressions in the understanding of tumor biology and development of various multifunctional drug delivery platforms may offer great promise for osteosarcoma treatment in the future, these nanomaterials are not well-developed for use in osteosarcoma patients for the present. Most of them are still at the cellular and animal experimental stage, and there is a long transitional period before clinical application [110]. More optimized nanocarriers for demanded drug delivery will be obtained after overcoming some challenges [78, 107], for example, 1) An ideal drug delivery system should selectively accumulate in the tumor sites, thus deeper understanding of the osteosarcoma targeting mechanism should be further explored for finding more specific target ligands; 2) Accumulation of nanocarriers in the liver is a common challenge for all drug delivery nanoplatforms; 3) Light currently used for photothermal therapy has a limited penetration ability towards deep tumors, therefore other alternative strategies should be developed; 4) Long-term biosafety of some of these nanomaterials should be systematically evaluated using more relevant animal models In vivo, and furthermore, animal models are different from human tissue, after all.

\section{Acknowledgments}

This work was supported by the Grants from The National Key Research and Development Program of China (2016YFC1100100), Grants from Major Research Plan of National Natural Science Foundation of China (91649204) and Grants from Natural Science Foundation of Hubei Province (2018CFB118).

\section{Author contributions}

Conceptualization, S.-Y. W., X.-C. Q. and Z.-W. S.; writing-original draft preparation, S.-Y W. and H.-Z. H.; writing-review and editing, X.-C. Q. and Z.-W. S.; funding acquisition, Z.-C. Z. and Z.-W.S.

\section{Competing Interests}

The authors have declared that no competing interest exists.

\section{References}

1. Savvidou OD, Bolia IK, Chloros GD, Goumenos SD, Sakellariou VI, Galanis EC, et al. Applied Nanotechnology and Nanoscience in Orthopedic Oncology. Orthopedics. 2016; 39: 280-6.

2. Saha RN, Vasanthakumar S, Bende G, Snehalatha M. Nanoparticulate drug delivery systems for cancer chemotherapy. Mol Membr Biol. 2010; 27: 215-31.

3. Alavi M, Hamidi M. Passive and active targeting in cancer therapy by liposomes and lipid nanoparticles. Drug Metab Pers Ther. 2019; 34.

4. Rodriguez-Nogales C, Gonzalez-Fernandez Y, Aldaz A, Couvreur P, Blanco-Prieto MJ. Nanomedicines for Pediatric Cancers. ACS Nano. 2018; 12: 7482-96.

5. Li Y, Lv S, Song Z, Dang J, Li X, He H, et al. Photodynamic therapy-mediated remote control of chemotherapy toward synergistic anticancer treatment. Nanoscale. 2018; 10: 14554-62

6. Tu Z, Qiao H, Yan Y, Guday G, Chen W, Adeli M, et al. Directed Graphene-Based Nanoplatforms for Hyperthermia: Overcoming Multiple Drug Resistance. Angew Chem Int Ed Engl. 2018; 57: 11198-202.

7. Gu W, Wu C, Chen J, Xiao Y. Nanotechnology in the targeted drug delivery for bone diseases and bone regeneration. Int J Nanomed. 2013; 8: 2305-17.

8. Kumari P, Ghosh B, Biswas S. Nanocarriers for cancer-targeted drug delivery. J Drug Target. 2016; 24: 179-91.

9. Bishop MW, Janeway KA, Gorlick R. Future directions in the treatment of osteosarcoma. Curr Opin Pediatr. 2016; 28: 26-33.

10. Mirabello L, Troisi RJ, Savage SA. Osteosarcoma incidence and survival rates from 1973 to 2004: data from the Surveillance, Epidemiology, and End Results Program. Cancer. 2009; 115: 1531-43.

11. Wang L, Xue GB. Catalpol suppresses osteosarcoma cell proliferation through blocking epithelial-mesenchymal transition (EMT) and inducing apoptosis. Biochem Biophys Res Commun. 2018; 495: 27-34.

12. Chawla SP, Chua VS, Fernandez L, Quon D, Saralou A, Blackwelder WC, et al Phase I/II and phase II studies of targeted gene delivery In vivo: intravenous Rexin-G for chemotherapy-resistant sarcoma and osteosarcoma. Mol Ther. 2009; 17: 1651-7.

13. Li S, Zhang $\mathrm{T}, \mathrm{Xu} \mathrm{W}$, Ding J, Yin F, Xu J, et al. Sarcoma-Targeting Peptide-Decorated Polypeptide Nanogel Intracellularly Delivers Shikonin for Upregulated Osteosarcoma Necroptosis and Diminished Pulmonary Metastasis. Theranostics. 2018; 8: 1361-75.

14. Chen F, Zeng Y, Qi X, Chen Y, Ge Z, Jiang Z, et al. Targeted salinomycin delivery with EGFR and CD133 aptamers based dual-ligand lipid-polymer nanoparticles to both osteosarcoma cells and cancer stem cells. Nanomedicine. 2018; 14: 2115-27.

15. Menezes PDP, Andrade TA, Frank LA, de Souza E, Trindade G, Trindade IAS, et al. Advances of nanosystems containing cyclodextrins and their applications in pharmaceuticals. Int J Pharm. 2019; 559: 312-28.

16. Bulbake U, Doppalapudi S, Kommineni N, Khan W. Liposomal Formulations in Clinical Use: An Updated Review. Pharmaceutics. 2017; 9.

17. He K, Tang M. Safety of novel liposomal drugs for cancer treatment: Advances and prospects. Chem Biol Interact. 2018; 295: 13-9.

18. Skubitz KM. Phase II trial of pegylated-liposomal doxorubicin (Doxil) in sarcoma. Cancer Invest. 2003; 21: 167-76.

19. Abu Lila AS, Ishida T. Liposomal Delivery Systems: Design Optimization and Current Applications. Biol Pharm Bull. 2017; 40: 1-10.

20. Meyers PA, Chou AJ. Muramyl tripeptide-phosphatidyl ethanolamine encapsulated in liposomes (L-MTP-PE) in the treatment of osteosarcoma. Adv Exp Med Biol. 2014; 804: 307-21.

21. Caliskan Y, Dalgic AD, Gerekci S, Gulec EA, Tezcaner A, Ozen C, et al. A new therapeutic combination for osteosarcoma: Gemcitabine and Clofazimine co-loaded liposomal formulation. Int J Pharm. 2019; 557: 97-104.

22. Liu Y, Zhang X, Liu Z, Wang L, Luo L, Wang M, et al. Gold nanoshell-based betulinic acid liposomes for synergistic chemo-photothermal therapy. Nanomedicine. 2017; 13: 1891-900.

23. Haghiralsadat F, Amoabediny G, Sheikhha MH, Zandieh-Doulabi B, Naderinezhad S, Helder $\mathrm{MN}$, et al. New liposomal doxorubicin nanoformulation for osteosarcoma: Drug release kinetic study based on thermo and pH sensitivity. Chem Biol Drug Des. 2017; 90: 368-79.

24. Chi Y, Yin X, Sun K, Feng S, Liu J, Chen D, et al. Redox-sensitive and hyaluronic acid functionalized liposomes for cytoplasmic drug delivery to osteosarcoma in animal models. J Control Release. 2017; 261: 113-25. 
25. Yin X, Chi Y, Guo C, Feng S, Liu J, Sun K, et al. Chitooligosaccharides Modified Reduction-Sensitive Liposomes: Enhanced Cytoplasmic Drug Delivery and Osteosarcomas-Tumor Inhibition in Animal Models. Pharm Res. 2017; 34: 2172-84.

26. Haghiralsadat F, Amoabediny G, Naderinezhad S, Forouzanfar T, Helder MN, Zandieh-Doulabi B. Preparation of PEGylated cationic nanoliposome-siRNA complexes for cancer therapy. Artif Cells Nanomed Biotechnol. 2018; 46: 684-92.

27. Haghiralsadat F, Amoabediny G, Naderinezhad S, Zandieh-Doulabi B, Forouzanfar T, Helder MN. Codelivery of doxorubicin and JIP1 siRNA with novel EphA2-targeted PEGylated cationic nanoliposomes to overcome osteosarcoma multidrug resistance. Int J Nanomed. 2018; 13: 3853-66.

28. Doppalapudi S, Jain A, Domb AJ, Khan W. Biodegradable polymers for targeted delivery of anti-cancer drugs. Expert Opin Drug Deliv. 2016; 13: 891-909.

29. Calzoni E, Cesaretti A, Polchi A, Di Michele A, Tancini B, Emiliani C. Biocompatible Polymer Nanoparticles for Drug Delivery Applications in Cancer and Neurodegenerative Disorder Therapies. J Funct Biomater. 2019; 10.

30. Suksiriworapong J, Taresco V, Ivanov DP, Styliari ID, Sakchaisri K, Junyaprasert VB, et al. Synthesis and properties of a biodegradable polymer-drug conjugate: Methotrexate-poly(glycerol adipate). Colloids Surf B Biointerfaces. 2018; 167: 115-25.

31. Martella E, Ferroni C, Guerrini A, Ballestri M, Columbaro M, Santi S, et al. Functionalized Keratin as Nanotechnology-Based Drug Delivery System for the Pharmacological Treatment of Osteosarcoma. Int J Mol Sci. 2018; 19.

32. Ni M, Xiong M, Zhang X, Cai G, Chen $H$, Zeng Q, et al. Poly(lactic-co-glycolic acid) nanoparticles conjugated with CD133 aptamers for targeted salinomycin delivery to CD133+ osteosarcoma cancer stem cells. Int J Nanomed. 2015; 10: 2537-54.

33. Duan R, Li C, Wang F, Yangi JC. Polymer-lipid hybrid nanoparticles-based paclitaxel and etoposide combinations for the synergistic anticancer efficacy in osteosarcoma. Colloids Surf B Biointerfaces. 2017; 159: 880-7.

34. Feng S, Wu ZX, Zhao Z, Liu J, Sun K, Guo C, et al. Engineering of Bone- and CD44-Dual-Targeting Redox-Sensitive Liposomes for the Treatment of Orthotopic Osteosarcoma. ACS Appl Mater Interfaces. 2019; 11: 7357-68.

35. Qhattal HS, Hye T, Alali A, Liu X. Hyaluronan polymer length, grafting density, and surface poly(ethylene glycol) coating influence In vivo circulation and tumor targeting of hyaluronan-grafted liposomes. ACS Nano. 2014; 8: 5423-40.

36. Zhang Y, Wang F, Li M, Yu Z, Qi R, Ding J, et al. Self-Stabilized Hyaluronate Nanogel for Intracellular Codelivery of Doxorubicin and Cisplatin to Osteosarcoma. Adv Sci (Weinheim, Ger). 2018; 5: 1700821.

37. Kedar U, Phutane P, Shidhaye S, Kadam V. Advances in polymeric micelles for drug delivery and tumor targeting. Nanomedicine. 2010; 6: 714-29.

38. Isoglu IA, Ozsoy Y, Isoglu SD. Advances in Micelle-based Drug Delivery: Cross-linked Systems. Curr Top Med Chem. 2017; 17: 1469-89.

39. Maran A, Yaszemski MJ, Kohut A, Voronov A. Curcumin and Osteosarcoma: Can Invertible Polymeric Micelles Help? Materials (Basel). 2016; 9.

40. Low SA, Yang J, Kopecek J. Bone-targeted acid-sensitive doxorubicin conjugate micelles as potential osteosarcoma therapeutics. Bioconjug Chem. 2014; 25: 2012-20.

41. Noy JM, Lu H, Hogg PJ, Yang JL, Stenzel M. Direct Polymerization of the Arsenic Drug PENAO to Obtain Nanoparticles with High Thiol-Reactivity and Anti-Cancer Efficiency. Bioconjug Chem. 2018; 29: 546-58.

42. Fang Z, Sun Y, Xiao H, Li P, Liu M, Ding F, et al. Targeted osteosarcoma chemotherapy using RGD peptide-installed doxorubicin-loaded biodegradable polymeric micelle. Biomed Pharmacother. 2017; 85: 160-8.

43. Yu W, Ye M, Zhu J, Wang Y, Liang C, Tang J, et al. Zinc phthalocyanine encapsulated in polymer micelles as a potent photosensitizer for the photodynamic therapy of osteosarcoma. Nanomedicine. 2018; 14: 1099-110.

44. Cajot S, Lautram N, Passirani C, Jerome C. Design of reversibly core cross-linked micelles sensitive to reductive environment. J Control Release. 2011; 152: 30-6.

45. Wang H, Huang Q, Chang H, Xiao J, Cheng Y. Stimuli-responsive dendrimers in drug delivery. Biomater Sci. 2016; 4: 375-90.

46. Palmerston Mendes L, Pan J, Torchilin VP. Dendrimers as Nanocarriers for Nucleic Acid and Drug Delivery in Cancer Therapy. Molecules. 2017; 22.

47. $\mathrm{Hu} \mathrm{J}, \mathrm{Hu} \mathrm{K}$, Cheng $\mathrm{Y}$. Tailoring the dendrimer core for efficient gene delivery. Acta Biomater. 2016; 35: 1-11.

48. Abedi-Gaballu F, Dehghan G, Ghaffari M, Yekta R, Abbaspour-Ravasjani S, Baradaran B, et al. PAMAM dendrimers as efficient drug and gene delivery nanosystems for cancer therapy. Appl Mater Today. 2018; 12: 177-90.

49. Madaan K, Kumar S, Poonia N, Lather V, Pandita D. Dendrimers in drug delivery and targeting: Drug-dendrimer interactions and toxicity issues. J Pharm Bioallied Sci. 2014; 6: 139-50.

50. Goncalves M, Maciel D, Capelo D, Xiao S, Sun W, Shi X, et al. Dendrimer-assisted formation of fluorescent nanogels for drug delivery and intracellular imaging. Biomacromolecules. 2014; 15: 492-9.

51. Wang Y, Li L, Shao N, Hu Z, Chen H, Xu L, et al. Triazine-modified dendrimer for efficient TRAIL gene therapy in osteosarcoma. Acta Biomater. 2015; 17: 115-24.

52. Soleymaniha M, Shahbazi MA, Rafieerad AR, Maleki A, Amiri A. Promoting Role of MXene Nanosheets in Biomedical Sciences: Therapeutic and Biosensing Innovations. Adv Healthc Mater. 2019; 8: e1801137.
53. Ibrahim M, Sabouni R, Husseini GA. Anti-cancer Drug Delivery Using Metal Organic Frameworks (MOFs). Curr Med Chem. 2017; 24: 193-214.

54. Singh P, Pandit S, Mokkapati V, Garg A, Ravikumar V, Mijakovic I. Gold Nanoparticles in Diagnostics and Therapeutics for Human Cancer. Int J Mol Sci. 2018; 19

55. Riley RS, Day ES. Gold nanoparticle-mediated photothermal therapy: applications and opportunities for multimodal cancer treatment. Wiley Interdiscip Rev Nanomed Nanobiotechnol. 2017; 9

56. Rahim M, Iram S, Khan MS, Khan MS, Shukla AR, Srivastava AK, et al. Glycation-assisted synthesized gold nanoparticles inhibit growth of bone cancer cells. Colloids Surf B Biointerfaces. 2014; 117: 473-9.

57. Steckiewicz KP, Barcinska E, Malankowska A, Zauszkiewicz-Pawlak A, Nowaczyk G, Zaleska-Medynska A, et al. Impact of gold nanoparticles shape on their cytotoxicity against human osteoblast and osteosarcoma in In vitro model. Evaluation of the safety of use and anti-cancer potential. J Mater Sci Mater Med. 2019; 30: 22.

58. Sanchez-Paradinas $\mathrm{S}$, Perez-Andres M, Almendral-Parra MJ, Rodriguez-Fernandez E, Millan A, Palacio F, et al. Enhanced cytotoxic activity of bile acid cisplatin derivatives by conjugation with gold nanoparticles. J Inorg Biochem. 2014; 131: 8-11.

59. Iram S, Zahera M, Khan S, Khan I, Syed A, Ansary AA, et al. Gold nanoconjugates reinforce the potency of conjugated cisplatin and doxorubicin. Colloids Surf B Biointerfaces. 2017; 160: 254-64.

60. Cebrian V, Martin-Saavedra F, Yague C, Arruebo M, Santamaria J, Vilaboa N. Size-dependent transfection efficiency of PEI-coated gold nanoparticles. Acta Biomater. 2011; 7: 3645-55.

61. Kovacs D, Igaz N, Keskeny C, Belteky P, Toth T, Gaspar R, et al. Silver nanoparticles defeat p53-positive and p53-negative osteosarcoma cells by triggering mitochondrial stress and apoptosis. Sci Rep. 2016; 6: 27902.

62. Fageria L, Pareek V, Dilip RV, Bhargava A, Pasha SS, Laskar IR, et al. Biosynthesized Protein-Capped Silver Nanoparticles Induce ROS-Dependent Proapoptotic Signals and Prosurvival Autophagy in Cancer Cells. ACS Omega. 2017; 2: 1489-504

63. Sha B, Gao W, Han Y, Wang S, Wu J, Xu F, et al. Potential application of titanium dioxide nanoparticles in the prevention of osteosarcoma and chondrosarcoma recurrence. J Nanosci Nanotechnol. 2013; 13: 1208-11.

64. Iram S, Khan S, Ansary AA, Arshad M, Siddiqui S, Ahmad E, et al. Biogenic terbium oxide nanoparticles as the vanguard against osteosarcoma. Spectrochim Acta A Mol Biomol Spectrosc. 2016; 168: 123-31.

65. Sisubalan N, Ramkumar VS, Pugazhendhi A, Karthikeyan C, Indira K, Gopinath $\mathrm{K}$, et al. ROS-mediated cytotoxic activity of $\mathrm{ZnO}$ and $\mathrm{CeO} 2$ nanoparticles synthesized using the Rubia cordifolia L. leaf extract on MG-63 human osteosarcoma cell lines. Environ Sci Pollut Res Int. 2018; 25: 10482-92.

66. Jurek PM, Zablocki K, Wasko U, Mazurek MP, Otlewski J, Jelen F. Anti-FGFR1 aptamer-tagged superparamagnetic conjugates for anticancer hyperthermia therapy. Int J Nanomed. 2017; 12: 2941-50.

67. Du S, Li J, Du C, Huang Z, Chen G, Yan W. Overendocytosis of superparamagnetic iron oxide particles increases apoptosis and triggers autophagic cell death in human osteosarcoma cell under a spinning magnetic field. Oncotarget. 2017; 8: 9410-24

68. Mondal S, Manivasagan P, Bharathiraja S, Santha Moorthy M, Nguyen VT, $\mathrm{Kim} \mathrm{HH}$, et al. Hydroxyapatite Coated Iron Oxide Nanoparticles: A Promising Nanomaterial for Magnetic Hyperthermia Cancer Treatment. Nanomaterials (Basel). 2017; 7.

69. Popescu RC, Andronescu E, Vasile BS, Trusca R, Boldeiu A, Mogoanta L, et al. Fabrication and Cytotoxicity of Gemcitabine-Functionalized Magnetite Nanoparticles. Molecules. 2017; 22.

70. Hartono SB, Yu M, Gu W, Yang J, Strounina E, Wang X, et al. Synthesis of multi-functional large pore mesoporous silica nanoparticles as gene carriers. Nanotechnology. 2014; 25: 055701.

71. Li T, Shi S, Goel S, Shen X, Xie X, Chen Z, et al. Recent advancements in mesoporous silica nanoparticles towards therapeutic applications for cancer. Acta Biomater. 2019; 89: 1-13.

72. Kesse S, Boakye-Yiadom KO, Ochete BO, Opoku-Damoah Y, Akhtar F, Filli MS, et al. Mesoporous Silica Nanomaterials: Versatile Nanocarriers for Cancer Theranostics and Drug and Gene Delivery. Pharmaceutics. 2019; 11.

73. Shahabi S, Doscher S, Bollhorst T, Treccani L, Maas M, Dringen R, et al. Enhancing Cellular Uptake and Doxorubicin Delivery of Mesoporous Silica Nanoparticles via Surface Functionalization: Effects of Serum. ACS Appl Mater Interfaces. 2015; 7: 26880-91.

74. Xiong L, Bi J, Tang Y, Qiao SZ. Magnetic Core-Shell Silica Nanoparticles with Large Radial Mesopores for siRNA Delivery. Small. 2016; 12: 4735-42.

75. Paris JL, Manzano M, Cabanas MV, Vallet-Regi M. Mesoporous silica nanoparticles engineered for ultrasound-induced uptake by cancer cells. Nanoscale. 2018; 10: 6402-8

76. Martinez-Carmona M, Lozano D, Colilla M, Vallet-Regi M. Lectin-conjugated $\mathrm{pH}$-responsive mesoporous silica nanoparticles for targeted bone cancer treatment. Acta Biomater. 2018; 65: 393-404.

77. Lu Y, Li L, Lin Z, Li M, Hu X, Zhang Y, et al. Enhancing Osteosarcoma Killing and CT Imaging Using Ultrahigh Drug Loading and NIR-Responsive Bismuth Sulfide@Mesoporous Silica Nanoparticles. Adv Healthc Mater. 2018; 7: e1800602.

78. Augustine S, Singh J, Srivastava M, Sharma M, Das A, Malhotra BD. Recent advances in carbon based nanosystems for cancer theranostics. Biomater Sci. 2017; 5: 901-52. 
79. Zhang W, Zhang Z, Zhang Y. The application of carbon nanotubes in target drug delivery systems for cancer therapies. Nanoscale Res Lett. 2011; 6: 555.

80. Peng Z, Miyanji EH, Zhou Y, Pardo J, Hettiarachchi SD, Li S, et al. Carbon dots: promising biomaterials for bone-specific imaging and drug delivery. Nanoscale. 2017; 9: 17533-43.

81. Zhao Q, Lin Y, Han N, Li X, Geng H, Wang X, et al. Mesoporous carbon nanomaterials in drug delivery and biomedical application. Drug Deliv. 2017; 24: 94-107.

82. Maiti D, Tong X, Mou X, Yang K. Carbon-Based Nanomaterials for Biomedical Applications: A Recent Study. Front Pharmacol. 2018; 9: 1401.

83. Tang Z, Zhao L, Yang Z, Liu Z, Gu J, Bai B, et al. Mechanisms of oxidative stress, apoptosis, and autophagy involved in graphene oxide nanomaterial anti-osteosarcoma effect. Int J Nanomed. 2018; 13: 2907-19.

84. Cicuendez M, Flores J, Oliveira H, Portoles MT, Vallet-Regi M, Vila M, et al. Metabolomic response of osteosarcoma cells to nanographene oxide-mediated hyperthermia. Mater Sci Eng C Mater Biol Appl. 2018; 91: 340-8.

85. Saravanabhavan SS, Rethinasabapathy M, Zsolt S, Kalambettu AB, Elumalai S, Janakiraman M, et al. Graphene oxide functionalized with chitosan based nanoparticles as a carrier of siRNA in regulating Bcl-2 expression on Saos-2 \& MG-63 cancer cells and its inflammatory response on bone marrow derived cells from mice. Mater Sci Eng C Mater Biol Appl. 2019; 99: 1459-68.

86. Li L, Luo C, Song Z, Reyes-Vargas E, Clayton F, Huang J, et al. Association of anti-HER2 antibody with graphene oxide for curative treatment of osteosarcoma. Nanomedicine. 2018; 14: 581-93.

87. Yan X, Yang W, Shao Z, Yang S, Liu X. Triggering of apoptosis in osteosarcoma cells by graphene/single-walled carbon nanotube hybrids via the ROS-mediated mitochondrial pathway. J Biomed Mater Res A. 2017; 105: 443-53.

88. Cheng Q, Blais MO, Harris GM, Jabbarzadeh E. PLGA-carbon nanotube conjugates for intercellular delivery of caspase-3 into osteosarcoma cells. PLoS One. 2013; 8: e81947.

89. Zhang B, Chen Q, Tang H, Xie Q, Ma M, Tan L, et al. Characterization of and biomolecule immobilization on the biocompatible multi-walled carbon nanotubes generated by functionalization with polyamidoamine dendrimers. Colloids Surf B Biointerfaces. 2010; 80: 18-25.

90. Miao Y, Zhang H, Pan Y, Ren J, Ye M, Xia F, et al. Single-walled carbon nanotube: One specific inhibitor of cancer stem cells in osteosarcoma upon downregulation of the TGFbeta1 signaling. Biomaterials. 2017; 149: 29-40.

91. Khan MA, Wu VM, Ghosh S, Uskokovic V. Gene delivery using calcium phosphate nanoparticles: Optimization of the transfection process and the effects of citrate and poly(l-lysine) as additives. J Colloid Interface Sci. 2016; 471: $48-58$

92. Maia ALC, Ferreira CA, Barros ALB, ATM ES, Ramaldes GA, Silva Cunha Junior $\mathrm{AD}$, et al. Vincristine-loaded hydroxyapatite nanoparticles as a potential delivery system for bone cancer therapy. J Drug Target. 2018; 26: 592-603.

93. Son KD, Kim YJ. Anticancer activity of drug-loaded calcium phosphate nanocomposites against human osteosarcoma. Biomater Res. 2017; 21: 13 .

94. Victor SP, Paul W, Sharma CP. Calcium phosphate nanoplatforms for drug delivery and theranostic applications. Drug Delivery Nanosystems for Biomedical Applications: Elsevier; 2018. p. 163-79.

95. Boanini E, Torricelli P, Boga C, Micheletti G, Cassani MC, Fini M, et al. (9R)-9-Hydroxystearate-Functionalized Hydroxyapatite as Antiproliferative and Cytotoxic Agent toward Osteosarcoma Cells. Langmuir. 2016; 32: 188-94.

96. Wang Y, Wang J, Hao H, Cai M, Wang S, Ma J, et al. In vitro and In vivo Mechanism of Bone Tumor Inhibition by Selenium-Doped Bone Mineral Nanoparticles. ACS Nano. 2016; 10: 9927-37.

97. Wu VM, Mickens J, Uskokovic V. Bisphosphonate-Functionalized Hydroxyapatite Nanoparticles for the Delivery of the Bromodomain Inhibitor JQ1 in the Treatment of Osteosarcoma. ACS Appl Mater Interfaces. 2017; 9: 25887-904.

98. Han Y, LiS, Cao X, Yuan L, Wang Y, Yin Y, et al. Different inhibitory effect and mechanism of hydroxyapatite nanoparticles on normal cells and cancer cells In vitro and In vivo. Sci Rep. 2014; 4: 7134

99. Kwon IK, Lee SC, Han B, Park K. Analysis on the current status of targeted drug delivery to tumors. J Control Release. 2012; 164: 108-14.

100. Ruttala HB, Ramasamy T, Madeshwaran T, Hiep TT, Kandasamy U, Oh KT, et al. Emerging potential of stimulus-responsive nanosized anticancer drug delivery systems for systemic applications. Arch Pharm Res. 2018; 41: 111-29.

101. Cabral H, Kataoka K. Progress of drug-loaded polymeric micelles into clinical studies. J Control Release. 2014; 190: 465-76.

102. Bahrami B, Hoijat-Farsangi M, Mohammadi H, Anvari E, Ghalamfarsa G, Yousefi $\mathrm{M}$, et al. Nanoparticles and targeted drug delivery in cancer therapy. Immunol Lett. 2017; 190: 64-83

103. Li Volsi A, Scialabba C, Vetri V, Cavallaro G, Licciardi M, Giammona G. Near-Infrared Light Responsive Folate Targeted Gold Nanorods for Combined Photothermal-Chemotherapy of Osteosarcoma. ACS Appl Mater Interfaces. 2017; 9: 14453-69.

104. Ai JW, Liu B, Liu WD. Folic acid-tagged titanium dioxide nanoparticles for enhanced anticancer effect in osteosarcoma cells. Mater Sci Eng C Mater Biol Appl. 2017; 76: 1181-7.

105. Dhule SS, Penfornis P, He J, Harris MR, Terry T, John V, et al. The combined effect of encapsulating curcumin and C6 ceramide in liposomal nanoparticles against osteosarcoma. Mol Pharm. 2014; 11: 417-27.
106. Rotman SG, Grijpma DW, Richards RG, Moriarty TF, Eglin D, Guillaume O. Drug delivery systems functionalized with bone mineral seeking agents for bone targeted therapeutics. J Control Release. 2018; 269: 88-99.

107. Morton SW, Shah NJ, Quadir MA, Deng ZJ, Poon Z, Hammond PT. Osteotropic therapy via targeted layer-by-layer nanoparticles. Adv Healthc Mater. 2014; 3: 867-75.

108. Rudnick-Glick S, Corem-Salkmon E, Grinberg I, Margel S. Targeted drug delivery of near IR fluorescent doxorubicin-conjugated poly(ethylene glycol) bisphosphonate nanoparticles for diagnosis and therapy of primary and metastatic bone cancer in a mouse model. J Nanobiotechnology. 2016; 14: 80.

109. Yin Q, Tang L, Cai K, Tong R, Sternberg R, Yang X, et al. Pamidronate functionalized nanoconjugates for targeted therapy of focal skeletal malignant osteolysis. Proc Natl Acad Sci U S A. 2016; 113: E4601-9.

110. Li CJ, Liu XZ, Zhang L, Chen LB, Shi X, Wu SJ, et al. Advances in Bone-targeted Drug Delivery Systems for Neoadjuvant Chemotherapy for Osteosarcoma. Orthop Surg. 2016; 8: 105-10.

111. Chen K, Liu B, Yu B, Zhong W, Lu Y, Zhang J, et al. Advances in the development of aptamer drug conjugates for targeted drug delivery. Wiley Interdiscip Rev Nanomed Nanobiotechnol. 2017; 9.

112. Moosavian SA, Sahebkar A. Aptamer-functionalized liposomes for targeted cancer therapy. Cancer Lett. 2019; 448: 144-54.

113. Liang C, Li F, Wang L, Zhang ZK, Wang C, He B, et al. Tumor cell-targeted delivery of CRISPR/Cas9 by aptamer-functionalized lipopolymer for therapeutic genome editing of VEGFA in osteosarcoma. Biomaterials. 2017; 147: $68-85$

114. Gui K, Zhang X, Chen F, Ge Z, Zhang S, Qi X, et al. Lipid-polymer nanoparticles with CD133 aptamers for targeted delivery of all-trans retinoic acid to osteosarcoma initiating cells. Biomed Pharmacother. 2019; 111: 751-64.

115. Yu Z, Chen F, Qi X, Dong Y, Zhang Y, Ge Z, et al. Epidermal growth factor receptor aptamer-conjugated polymer-lipid hybrid nanoparticles enhance salinomycin delivery to osteosarcoma and cancer stem cells. Exp Ther Med. 2018; 15: 1247-56.

116. Kim JH, Moon MJ, Kim DY, Heo SH, Jeong YY. Hyaluronic Acid-Based Nanomaterials for Cancer Therapy. Polymers (Basel). 2018; 10.

117. Xiao Z, Wan J, Nur AA, Dou P, Mankin H, Liu T, et al. Targeting CD44 by CRISPR-Cas9 in Multi-Drug Resistant Osteosarcoma Cells. Cell Physiol Biochem. 2018; 51: 1879-93.

118. Gupta A, Kaur CD, Saraf S, Saraf S. Targeting of herbal bioactives through folate receptors: a novel concept to enhance intracellular drug delivery in cancer therapy. J Recept Signal Transduct Res. 2017; 37: 314-23.

119. Wei X, Liao J, Davoudi Z, Zheng H, Chen J, Li D, et al. Folate Receptor-Targeted and GSH-Responsive Carboxymethyl Chitosan Nanoparticles Containing Covalently Entrapped 6-Mercaptopurine for Enhanced Intracellular Drug Delivery in Leukemia. Mar Drugs. 2018; 16.

120. Yang R, Kolb EA, Qin J, Chou A, Sowers R, Hoang B, et al. The folate receptor alpha is frequently overexpressed in osteosarcoma samples and plays a role in the uptake of the physiologic substrate 5-methyltetrahydrofolate. Clin Cancer Res. 2007; 13: 2557-67.

121. Wang F, Pang JD, Huang LL, Wang R, Li D, Sun K, et al. Nanoscale polysaccharide derivative as an AEG-1 siRNA carrier for effective osteosarcoma therapy. Int J Nanomed. 2018; 13: 857-75.

122. Haghiralsadat F, Amoabediny G, Naderinezhad S, Nazmi K, De Boer JP, Zandieh-Doulabi B, et al. EphA2 Targeted Doxorubicin-Nanoliposomes for Osteosarcoma Treatment. Pharm Res. 2017; 34: 2891-900.

123. Posthumadeboer J, Piersma SR, Pham TV, van Egmond PW, Knol JC, Cleton-Jansen AM, et al. Surface proteomic analysis of osteosarcoma identifies EPHA2 as receptor for targeted drug delivery. Br J Cancer. 2013; 109: 2142-54.

124. Luetke A, Meyers PA, Lewis I, Juergens H. Osteosarcoma treatment - where do we stand? A state of the art review. Cancer Treat Rev. 2014; 40: 523-32.

125. He Q, Guo S, Qian Z, Chen X. Development of individualized anti-metastasis strategies by engineering nanomedicines. Chem Soc Rev. 2015; 44: 6258-86.

126. Gonzalez-Fernandez $\mathrm{Y}$, Brown HK, Patino-Garcia A, Heymann D, Blanco-Prieto MJ. Oral administration of edelfosine encapsulated lipid nanoparticles causes regression of lung metastases in pre-clinical models of osteosarcoma. Cancer Lett. 2018; 430: 193-200.

127. Su L, Li R, Khan S, Clanton R, Zhang F, Lin YN, et al. Chemical Design of Both a Glutathione-Sensitive Dimeric Drug Guest and a Glucose-Derived Nanocarrier Host to Achieve Enhanced Osteosarcoma Lung Metastatic Anticancer Selectivity. J Am Chem Soc. 2018; 140: 1438-46.

128. Yu W, Wang Y, Zhu J, Jin L, Liu B, Xia K, et al. Autophagy inhibitor enhance $\mathrm{ZnPc} / \mathrm{BSA}$ nanoparticle induced photodynamic therapy by suppressing PD-L1 expression in osteosarcoma immunotherapy. Biomaterials. 2019; 192: $128-39$

129. Cai W, Wang J, Chu C, Chen W, Wu C, Liu G. Metal-Organic Framework-Based Stimuli-Responsive Systems for Drug Delivery. Adv Sci (Weinheim, Ger). 2019; 6: 1801526.

130. Hossen S, Hossain MK, Basher MK, Mia MNH, Rahman MT, Uddin MJ. Smart nanocarrier-based drug delivery systems for cancer therapy and toxicity studies: A review. J Adv Res. 2019; 15: 1-18.

131. Yang F, Wen X, Ke QF, Xie XT, Guo YP. pH-responsive mesoporous ZSM-5 zeolites/chitosan core-shell nanodisks loaded with doxorubicin against osteosarcoma. Mater Sci Eng C Mater Biol Appl. 2018; 85: 142-53.

132. Meshkini A, Oveisi H. Methotrexate-F127 conjugated mesoporous zinc hydroxyapatite as an efficient drug delivery system for overcoming 
chemotherapy resistance in osteosarcoma cells. Colloids Surf B Biointerfaces. 2017; 158: 319-30.

133. Yang S, Tang Z, Zhang D, Deng $\mathrm{M}$, Chen $\mathrm{X}$. $\mathrm{pH}$ and redox dual-sensitive polysaccharide nanoparticles for the efficient delivery of doxorubicin. Biomater Sci. 2017; 5: 2169-78.

134. Martinez-Carmona M, Lozano D, Baeza A, Colilla M, Vallet-Regi M. A novel visible light responsive nanosystem for cancer treatment. Nanoscale. 2017; 9: 15967-73.

135. Yang Y, Mu J, Xing B. Photoactivated drug delivery and bioimaging. Wiley Interdiscip Rev Nanomed Nanobiotechnol. 2017; 9.

136. Mai BT, Balakrishnan PB, Barthel MJ, Piccardi F, Niculaes D, Marinaro F, et al. Thermoresponsive Iron Oxide Nanocubes for an Effective Clinical Translation of Magnetic Hyperthermia and Heat-Mediated Chemotherapy. ACS Appl Mater Interfaces. 2019; 11: 5727-39.

137. Oliveira RR, Carriao MS, Pacheco MT, Branquinho LC, de Souza ALR, Bakuzis $\mathrm{AF}$, et al. Triggered release of paclitaxel from magnetic solid lipid nanoparticles by magnetic hyperthermia. Mater Sci Eng C Mater Biol Appl. 2018; 92: 547-53.

138. Jalili NA, Jaiswal MK, Peak CW, Cross LM, Gaharwar AK. Injectable nanoengineered stimuli-responsive hydrogels for on-demand and localized therapeutic delivery. Nanoscale. 2017; 9: 15379-89. 